\title{
Marcello SCHEMBRI, I trovatori: Musica e poesia. I primi cantautori della storia
}

\section{Christelle Chaillou-Amadieu}

\section{(2) OpenEdition}

\section{Journals}

Édition électronique

URL : https://journals.openedition.org/ccm/5185

DOI : $10.4000 / \mathrm{ccm} .5185$

ISSN : 2119-1026

\section{Éditeur}

Centre d'études supérieures de civilisation médiévale/Université de Poitiers

\section{Édition imprimée}

Date de publication : 1 septembre 2020

Pagination : 208

ISBN : 978-2-490783-06-9

ISSN : 0007-9731

Référence électronique

Christelle Chaillou-Amadieu, "Marcello schembRI, I trovatori: Musica e poesia. I primi cantautori della storia », Cahiers de civilisation médiévale [En ligne], 250-251 | 2020, mis en ligne le 01 septembre 2021, consulté le 26 novembre 2022. URL : http://journals.openedition.org/ccm/5185 ; DOI : https://doi.org/ $10.4000 / \mathrm{ccm} .5185$

\section{(c) (i) (3)}

Creative Commons - Attribution - Pas d'Utilisation Commerciale - Pas de Modification 4.0 International - CC BY-NC-ND 4.0

https://creativecommons.org/licenses/by-nc-nd/4.0/ 
Marcello SchemBri, I trovatori: Musica e poesia. I primi cantautori della storia, Varèse, Zecchini Editore, 2018.

L'ouvrage traite de la tradition musico-poétique des troubadours $\left(\mathrm{XII}^{\mathrm{e}}-\mathrm{XIII}^{\mathrm{e}} \mathrm{s}\right.$.) en douze chapitres et s'organise comme une synthèse de la question. Le premier chapitre s'intéresse à la définition du «trobar », du troubadour et du jongleur et, brièvement à l'espace de la performance, que l'on imagine dans la cour du seigneur, comme nous l'indiquent les textes (p. 12-14). L'a. explique ainsi, à l'aide d'exemples variés, que la réalité socio-culturelle montre que la distinction traditionnelle entre le troubadour (poète-compositeur) et le jongleur (interprète) ne correspond pas exactement à ce que nous disent les textes (p. 8). Le chapitre 2 retrace les grandes lignes de la tradition troubadouresque, de son origine, encore très débattue, à sa disparition. Il discute par ex. les trois principales hypothèses évoquées jusqu'à présent (p. $16:$ la tradition populaire, la poésie médiolatine et la poésie arabo-andalouse) pour s'intéresser ensuite à l'expansion de la tradition dans la France septentrionale, dans la péninsule Ibérique, dans l'espace germanique et en Italie. Dans un troisième chapitre, «La poetica », l'a. définit l'amour courtois et les valeurs véhiculées par les troubadours qui s'y rattachent (fin'amor, cortezia, mezura, pretz, etc.) tout en s'attardant sur la notion de joy en citant notamment la célèbre définition de Jean Frappier (p. 29), pour poursuivre sur l'espace linguistique ou la forme des coblas. Après un bref rappel de la tradition des vidas et des razos (chap. 4), textes narratifs contenant des éléments biographiques et thématiques de troubadours, M. Schembri reprend les définitions et les caractéristiques des genres poétiques données par les Leys d'amors (v. 1350) en distinguant les genres qui nous sont parvenus avec ou sans mélodies notées (chap. 5). Dans «La musica» (chap. 7), sont définies les différentes formes poético-musicales des chansons telles que les avaient établies Friedrich Gennrich (1932) puis Elizabeth Aubrey (1996), une description littéraire du langage musical, abordé notamment sous l'angle des émotions. Ensuite, l'a. donne quelques exemples très intéressants d'effets stylistiques, notamment des enjambements et leurs rapports avec la mélodie (p. 92-93) afin de montrer la possible adéquation dans la composition de la musique et celle du texte. Après une longue synthèse sur le rapport entre les mélodies des troubadours et le plain-chant, étayée par de nombreuses citations, M. Schembri montre des exemples de courbes musicales. La notation musicale fait l'objet également d'une description (p. 130-132) tout comme la tradition manuscrite avec une présentation des quatre principaux témoins qui conservent des mélodies de troubadours $(\mathrm{G}$ : Milan, Bibliothèque Ambrosienne, R 71 sup.; R : Paris BnF, fr. 22543; $\mathrm{W}$ : Paris BnF, fr. 844 et $\mathrm{X}$ : Paris BnF, fr. 20050). Les manuscrits ne conservant que des fragments musicaux ou uniquement textuels sont mentionnés dans un second temps (p. 150-152). Sont ensuite décrites les principales éditions musicales (Friedrich Gennrich, Ismael Fernández de la Cuesta, Ugo Sesini) qui représentent les différentes conceptions du répertoire (édition mesurée, semi-diplomatique, isochrone, etc.). Le chapitre 8 met en parallèle les méthodes de transcription des mélodies avec le problème du rythme, non indiqué dans le corpus des troubadours (la notation carrée employée n'indique que la hauteur des sons). La question rythmique des mélodies de troubadours préoccupe depuis longtemps les musicologues qui ont dans un premier temps principalement proposé des éditions mensurales (modales, ternaires, binaires), donc avec une reconstitution (réécriture) du rythme. Mais, comme le montre l'exemple de la p. 160, les diverses éditions d'une même chanson donnent des résultats très différents (p. 160-161 : Gennrich, Restori, Ludwig, etc.). La question de l'accompagnement musical (chap. 9) a également fait l'objet de diverses interprétations. Les mélodies de troubadours ont été transmises sans accompagnement musical alors que bon nombre de miniatures montrent une pratique avérée (p. 181). L'a. décrit ainsi quelques célèbres corpus de miniatures avec des représentations d'instruments (Cantigas de Santa Maria, Codex Manesse) ou encore des citations issues des textes narratifs (Roman de Flamenca, Lo Romans de Daurel $e$ de Beto). Quant à la performance à l'époque, il ne reste que des témoignages très indirects notamment dans les vidas et les razos (p. 193). L'ouvrage se tourne ensuite vers l'interprétation musicale actuelle du corpus (chap. 11 et 12) et s'attache à décrire les différentes orientations stylistiques des ensembles de musiques anciennes ou les corpus choisis dans la discographie.

Dans cet ouvrage interdisciplinaire, M. Schembri synthétise les principales notions de la tradition troubadouresque qu'il étaye d'une riche bibliographie. Le livre constitue non seulement un excellent support de valorisation, mais aussi un outil précieux pour ceux qui souhaitent avoir des connaissances essentielles sur ce corpus.

Christelle Chaillou-Amadieu UMR 7302 - CNRS/CESCM 